\title{
Metabolically Healthy Obesity and the Fit/Fat Phenotype: Associations with Mortality, Subclinical Cardiovascular Disease and Approach to Treatment
}

Ayesha Farooq ${ }^{1}$, Sufian Sorathia ${ }^{1}$, Sameer Shaharyar ${ }^{1,2}$, Lara Roberson ${ }^{2}$ and Hamid Feiz ${ }^{1^{*}}$

${ }^{1}$ Aventura Hospital and Medical Center, Aventura, USA

${ }^{2}$ Center for Prevention and Wellness Research, Baptist Health South Florida, Miami, FL 33139, USA

*Corresponding author: Hamid Feiz, Aventura Hospital and Medical Center, Aventura, FL 33180, USA, Tel: +1 305-682-7000, E-mail: hamid.feiz@hcahealthcare.com Rec date: Apr 09, 2015, Acc date: May 01, 2015, Pub date: May 04, 2015

Copyright: (c) 2015 Ayesha Farooq, et al. This is an open-access article distributed under the terms of the Creative Commons Attribution License, which permits unrestricted use, distribution, and reproduction in any medium, provided the original author and source are credited.

\begin{abstract}
Obesity is a global epidemic affecting over a third of the adult population. Within the obese, subgroups have been identified, including the metabolically healthy obese $(\mathrm{MHO})$ and the fit/fat phenotypes. The MHO phenotype was traditionally thought to have lower cardiovascular risk than the 'typically obese', a notion that is being challenged by recent data. Similarly, the emerging fit/fat phenotype is raising questions about the impact of obesity on mortality and cardiovascular risk. The present narrative review provides an overview of these phenotypes and summarizes current evidence and viewpoints regarding the same. The review then incorporates this data into a format that can be utilized by clinicians and researchers to aid clinical decision-making.
\end{abstract}

Keywords: Obesity; Cardiovascular diseases; Cholesterol

\section{Background}

Since 1980, worldwide obesity has more than doubled and continues to increase in prevalence. According to the World Health Organization, in 2014, more than 1.9 billion adults were overweight, which equates to roughly $39 \%$ of the adult population 1 . According to the Centers for Disease Control and Prevention, in the United States between 2011 and 2012, approximately 3 out of every 5 adults were overweight and more than one-third were obese, which equates to 78.6 million adults $[1,2]$. Obesity is a preventable risk factor of all-cause mortality, cardiovascular related mortality and cancer related mortality [3]. However, a subset of obese patients have been identified who do not display the typical obesity related metabolic disorders, and are thought to have a risk in between healthy-normal weight individuals and those with metabolic syndrome.

In the 1940s, Dr. Jean Vague was the first to observe a constellation of risk factors for diabetes mellitus, dyslipidemia and atherosclerosis in obese patients [4]. His "vague" observations led to recognition of metabolic syndrome as a cluster of related conditions conferring increased cardiovascular risk and have since led to many debates regarding its diagnosis, with a consensus definition being achieved only recently (Table 1) [5].

\begin{tabular}{|l|l|}
\hline Components & Values \\
\hline Central Obesity** & $\begin{array}{l}\text { Men Waist Circumference }>40 \text { inches } \\
\text { Women Waist Circumference }>35 \text { inches }\end{array}$ \\
\hline Hypertriglyceridemia*** & Triglycerides $>150 \mathrm{mg} / \mathrm{dL}$ \\
\hline Reduced HDL Cholesterol*** & $\begin{array}{l}\text { Men HDL cholesterol }<40 \mathrm{mg} / \mathrm{dL} \\
\text { Women HDL cholesterol }<50 \mathrm{mg} / \mathrm{dL}\end{array}$ \\
\hline Elevated Blood Pressure ${ }^{* * *}$ & Blood Pressure $>130 / 85 \mathrm{mmHg}$ \\
\hline Fasting Hyperglycemia*** & Blood Glucose $>100 \mathrm{mg} / \mathrm{dL}$ \\
\hline $\begin{array}{l}* \text { Criteria is based on components jointly agreed upon by International Diabetes Federation Task Force on Epidemiology and Prevention, National Heart, Lung, and } \\
\text { Blood Institute, American Heart Association, World Heart Federation, International Atherosclerosis Society, and International Association for the Study of Obesity }\end{array}$ & \\
\hline$* *$ Non-Europeans cut points (population and country-specific definitions) & \\
\hline
\end{tabular}

Table 1: Metabolic Syndrome Criteria (3 of the 5 must be present for diagnosis) ${ }^{\star 5}$

While originally associated with increased risk in all obese individuals, recent studies reveal that metabolic syndrome may not actually manifest in all with a high body mass index (BMI). In fact, studies have shown that up to $30 \%$ of the obese do not display the typical metabolic disorders of insulin resistance, dyslipidemia and hypertension [6-13] and actually display favorable inflammatory, hormonal, liver enzymes and immune profiles. This led to identification of a new subgroup within the obese population termed 
Citation: Farooq A, Sorathia S,Shaharyar S, Roberson L, Feiz H (2015) Metabolically Healthy Obesity and the Fit/Fat Phenotype: Associations with Mortality, Subclinical Cardiovascular Disease and Approach to Treatment. J Metabolic Synd 4: 176. doi:http://dx.doi.org/ 10.4172/2167-0943.1000176

Page 2 of 7

metabolically healthy obesity (MHO). MHO can be compared to the metabolically unhealthy but normal weight (MUNW), who have a normal BMI but display the typical metabolic disorders seen with obesity (Table 2) [7,10,12,14-19].

\begin{tabular}{|c|c|c|c|}
\hline \multicolumn{4}{|c|}{ Metabolic Health* } \\
\hline & & Healthy & Unhealthy \\
\hline \multirow[t]{2}{*}{ WEIGHT** } & Obese & Metabolically Healthy Obese (MHO) & $\begin{array}{l}\text { Metabolically Unhealthy Obese } \\
(\mathrm{MUO})=\text { Metabolic Syndrome }\end{array}$ \\
\hline & Normal & $\begin{array}{l}\text { Metabolically Healthy Normal Weight } \\
\text { (MHNW) }\end{array}$ & $\begin{array}{l}\text { Metabolically Unhealthy Normal Weight } \\
\text { (MUNW) }\end{array}$ \\
\hline
\end{tabular}

Table 2: Different Metabolic Phenotypes.

The present narrative review provides an overview of the MHO phenotype in the context of all-cause mortality and cardiovascular disease risk. We further discuss the biological associations of the MHO phenotype, as well as discuss the interplay of physical fitness and obesity status in determining CVD risk. Finally, the review offers suggestions for incorporating these data into clinical practice and assisting future research.

\section{One of the Many Faces of Obesity: The Mho Phenotype}

For a given BMI category, patients can be classified into subgroups based on the presence of metabolic risk factors (Table 2). This divides patients into the metabolically healthy normal weight (MHNW), metabolically unhealthy normal weight (MUNW), metabolically healthy obese (MHO) and the metabolically unhealthy obese (MUO) which, depending on the definition employed, can be synonymous with metabolic syndrome. Traditionally, obesity is graded into classes based on body mass index (BMI), either being classified as overweight $(\mathrm{BMI}>25$ and $<30)$ or obese $(\mathrm{BMI}>30)$. Some studies assessing metabolic risk in the context of overweight individuals categorize patients as metabolically healthy overweight (MH-Overweight) and metabolically healthy obese, whereas others merge these into the same category.

Metabolically healthy obesity was first identified in 2001 in terms of visceral adiposity and insulin resistance (IR) but since then, it has had various meanings. Most commonly, it has been defined as obesity with a range of 0,1 , or 2 features of metabolic syndrome [20], sometimes excluding patients with diabetes mellitus all together, but no standard definition for MHO has been established [12,21]. Other definitions of metabolic risk factors have included $\mathrm{C}$ reactive protein (CRP), white blood cell (WBC) count, insulin sensitivity, waist circumference, body fat percentage and combinations of the same. Although a consensus was reached on the definition of metabolic syndrome in 2009, published literature continues to define it differently making it difficult to compare results on this topic [22]. Depending on the definition employed, the prevalence of the MHO phenotype is thought to range from $10-32 \%$ of obese individuals $[11,13,23]$.

\section{Is MHO a "Benign" Phenotype?}

When the phenotype was first identified, MHO was thought to have a lower risk of cardiovascular disease and mortality than MUO and was interpreted as a 'benign' condition. Recent evidence [20,24], however, places MHO on a continuum with MHNW, MUNW, and MUO individuals as is demonstrated in Figure 1.

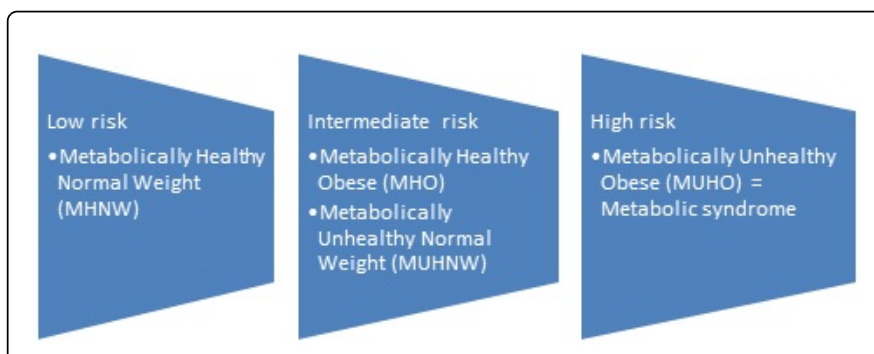

Figure 1: Risk for cardiovascular disease displayed as a continuum.

Kramer et al. [24] conducted a pooled analysis of unadjusted data from eight studies ( $n=61386 ; 3988$ events, follow-up range 3-30 years) and demonstrated that the MHO phenotype was associated with a $24 \%$ increased risk of all-cause mortality and CVD events as compared to the MHNW population (Table 3).

\begin{tabular}{|l|l|l|}
\hline Groups & Pooled Risk Estimate & Pooled Risk Estimate $>\mathbf{1 0 y}$ follow up \\
\hline MHNW (referent) & 1 & 1 \\
\hline MUNW & $3.14(2.36-3.93)$ & - \\
\hline MH-Overweight & $1.10(0.90-1.24)$ & $1.21(0.91-1.61)$ \\
\hline MH-Obese & $1.19(0.98-1.38)$ & $1.24(1.02-1.55)$ \\
\hline
\end{tabular}


Citation: Farooq A, Sorathia S,Shaharyar S, Roberson L, Feiz H (2015) Metabolically Healthy Obesity and the Fit/Fat Phenotype: Associations with Mortality, Subclinical Cardiovascular Disease and Approach to Treatment. J Metabolic Synd 4: 176. doi:http://dx.doi.org/ 10.4172/2167-0943.1000176

Page 3 of 7

\begin{tabular}{|l|l|l|}
\hline MU-Overweight & $2.70(2.08-3.30)$ & - \\
\hline MU-Obese & $2.65(2.18-3.12)$ & - \\
\hline
\end{tabular}

Table: 3a Pooled Risk Estimates for all-cause mortality and CVD events by metabolic and obesity category.

\begin{tabular}{|l|l|l|}
\hline Groups & Pooled Risk Estimate & Pooled Risk Estimate >10y follow up \\
\hline MUNW & 1 & - \\
\hline MU-Obese & $1.12(0.92-1.37)$ & - \\
\hline MU-Overweight & $1.13(0.93-1.37)$ & - \\
\hline Ref: Kramer et al.24 & \\
\hline
\end{tabular}

Table 3b: Pooled risk estimates for all-cause mortality and CVD events compared to metabolically unhealthy normal weight (MUNW) as referent.

However, this increased risk was not apparent in studies with follow-up durations of less than 10 years. This 10 year 'lag' period may explain the findings in initial published reports, which labeled MHO as a benign phenotype; since the risk increase is only evident after 10 years, studies with shorter follow-up durations would have yielded negative results despite the existence of a true association. Some studies suggest that metabolically healthy individuals may be younger than their metabolically unhealthy counter parts suggesting that over time, they too will develop CVD [25,26]. Additionally, the conversion of MHO to the higher risk MUO over time may explain this effect, as in 2 studies, MHO was seen to convert to MUO in 34.2\% [27] and $>50 \%$ of subjects over prolonged follow-up [28].

In contrast to these data, mortality risk in $\mathrm{MHO}$ individuals in NHANES III who were followed for approximately 15 years was determined to be similar to that of MHNW individuals [25]. However, the NHANES study had a relatively small number of subjects classified as MHO (A total of $40 \mathrm{MHO}$ out of 1160 obese) as compared to the Kramer analysis, which may have limited their ability to exclude a relationship.

Interestingly, in the Kramer meta-analysis [24], those who were overweight and metabolically healthy (distinct from obese and metabolically healthy) did not seem to have a higher risk of mortality or CVD events. This again is in favor with the "delayed injury" hypothesis, as the overweight individuals may progress to obesity over time, gaining the risk profile of that population, which would require a longer follow-up to detect this difference.

Having established that the MHO was associated with increased allcause mortality and/or CVD risk, Kramer et al. [24] further studied the effect of metabolic status across obesity groups by comparing the MUO and MU-overweight groups with the MUNW group. They noted no significant differences in mortality or CVD risk between these three groups. This is highly indicative of the relative importance of metabolic dysfunction and obesity in creating disease, in that it may be reasonable to consider metabolic dysfunction as the major contributor or primary risk factor for CVD, with obesity being a secondary or "enabling" risk factor, in that the absence of metabolic derangements seems to be more protective for mortality and CVD risk as compared to the absence of obesity (Figure 2).

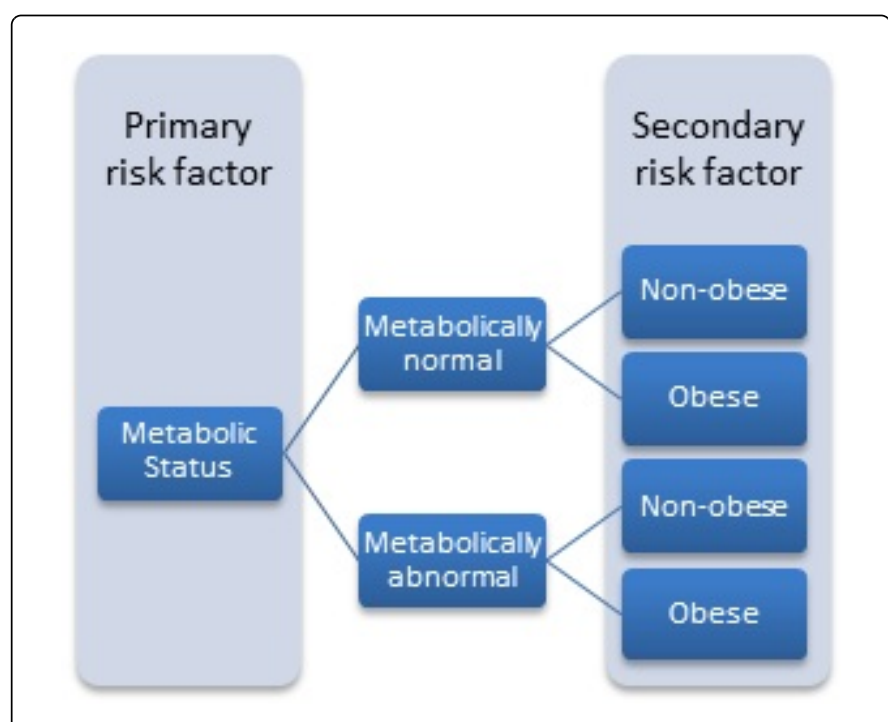

Figure 2: Metabolic Health as a Primary Risk Factor for Poor Outcome.

Alternatively, it may be reasonable to think of obesity as another "metabolic" risk factor rather than a means of primary stratification, a concept embraced in the unified diagnostic criteria for metabolic syndrome. This notion is supported by their observation that the MUNW group had a high overall risk (OR: 3.14), which was comparable to that of the MHO group. This is supported by data from the NHANES study [24], which documented an increased risk in MUNW individuals.

Regardless of the relative importance of metabolic status or obesity, the Kramer analysis and other data [20,29] demonstrate that the MHO phenotype is far from benign and does confer considerable increased risk for CVD and mortality, albeit possibly less than the risk conferred by the presence of both obesity and metabolic dysfunction. 
Citation: Farooq A, Sorathia S,Shaharyar S, Roberson L, Feiz H (2015) Metabolically Healthy Obesity and the Fit/Fat Phenotype: Associations with Mortality, Subclinical Cardiovascular Disease and Approach to Treatment. J Metabolic Synd 4: 176. doi:http://dx.doi.org/ 10.4172/2167-0943.1000176

Page 4 of 7

\section{MHO and Subclinical Atherosclerotic Disease}

Although a consensus has not been reached in literature, a number of studies have demonstrated an increase in subclinical CVD in the MHO group (Table 4) [26,27,30-35].

\begin{tabular}{|c|c|c|}
\hline Author, Year & $\mathbf{N}$ & Results \\
\hline Marini et al., 2007 [34] & 153 & $\uparrow$ CCA-IMT in MHO (0.79) vs MHNW (0.61), p<0.001 \\
\hline Lind et al. 2011 [33] & 1016 & $\begin{array}{l}\downarrow \text { vasoreactivity, } \uparrow \text { echolucent carotid artery wall, } \uparrow \text { left ventricular mass and function, impaired coagulation/fibrinolysis in } \\
\text { MHO vs MHNW ( } P<0.05 \text { to } 0.001)\end{array}$ \\
\hline Wildman et al., 2011 [35] & 1889 & $\uparrow \mathrm{CRP}, \mathrm{IL}-6$ in MHO vs. MHNW \\
\hline Khan et al., 2011 [32] & 3302 & $\uparrow \mathrm{CCA}-\mathrm{IMT}, \mathrm{CAC}, \mathrm{aPWV}$ in $\mathrm{MHO}$ vs. MHNW \\
\hline Heianza et al., 2014 [27] & 29564 & $\begin{array}{l}\uparrow \text { odds of developing diabetes (OR: } 2.32 ; 1.50-3.59 \text { ) in MHO vs MHNW over } 5 \text { years follow-up. This was attenuated after } \\
\text { adjusting for fatty liver, however, MHO with fatty liver was associated with } \uparrow \text { odds of incident diabetes. }\end{array}$ \\
\hline Jung et al., 2014 [31] & 4009 & $\begin{array}{l}\uparrow \text { abnormal MDCT findings (coronary artery stenosis, any plaque, calcified plaque, mixed plaque, CAC }>0 \text {, and CAC }>100 \text { ) in } \\
\text { MHO vs MHNW }\end{array}$ \\
\hline $\begin{array}{l}\text { Shaharyar et al., } 2015 \\
\text { [26] }\end{array}$ & 5519 & $\uparrow$ prevalence of hsCRP $\geq 3$ and hepatic steatosis in MHO vs MHNW \\
\hline $\begin{array}{l}\text { Indulekha et al., } 2015 \\
\text { [30] }\end{array}$ & 1304 & $\uparrow \mathrm{CRP}, \mathrm{TNF}-\alpha$, IL-6, MCP in MHO vs MHNW. \\
\hline
\end{tabular}

Table 4: Biological and Clinical Associations of the MHO phenotype - Summary of Selected Literature.

Roberson et al. [20], in a review, examined four studies reporting a mean difference in common carotid artery intima media thickness (CCA-IMT) between MHO and MHNW individuals, of which two reported significantly higher levels in the MHO. However, in the two studies that did not attain statistical significance, the mean CCA-IMT tended to be higher in the MHO group as compared to the MHNW.

Heianza et al. [27] demonstrated that MHO phenotype had a higher prevalence of hepatic steatosis $(47.8 \%$ vs $11.3 \%, \mathrm{p}<0.01)$ as compared to MHNW participants. The MHO phenotype was associated with higher odds of hepatic steatosis in age and gender adjusted models (OR: 6.70; 95\% CI 5.62-7.99). After development of hepatic steatosis (HS), MHO+ hepatic steatosis was associated with increased odds of incident diabetes. Similarly, Shaharyar et al. [26] documented an increased prevalence and odds of hepatic steatosis in the MHO group as compared to the MHNW group ( $40 \%$ vs $8 \%, \mathrm{p}<0.001$ and OR: 5.80 ; 95\% CI 4.72-7.13, respectively).

Lind et al. [33] examined 1016 individuals and found an increased subclinical atherosclerotic disease burden as assessed by a variety of markers in MHO versus the MHNW groups. Wildman et al. [35], and Indulekha et al. [30] demonstrated an increased inflammatory burden in patients with MHO. Khan et al. [32], demonstrated that in a series of 3302 participants, the MHO phenotype was associated with significantly altered carotid intima media thickness, coronary artery calcification and aortic pulse wave velocity in MHO patients as compared to their normal weight counterparts.

Among the various subclinical disease markers used to determine CVD risk, coronary artery calcification is perhaps the most robust in terms of predicting future CVD risk. CAC scores have been shown to consistently provide prognostic information above and beyond traditional cardiovascular risk factors [36-39] and CAC scoring is now incorporated into the AHA/ACCF clinical guidelines [40] for risk stratification in patients with indeterminate risk. Khan et al. [32] demonstrated that women with $\mathrm{MHO}$ were twice as likely to have coronary calcification (OR: 2.30; 95\% CI 1.20-4.70, p=0.013) compared to MHNW women. Jung et al. [31] examined 4009 individuals with multidetector CT scanning and found a significantly higher prevalence of coronary calcification (OR: 1.38; 95\% CI 1.04-1.82), and significantly higher prevalence of severe coronary calcification (OR: 1.69 ; 95\% CI 1.03-2.78) in MHO versus MHNW. Chang et al. [41] assessed CAC in a large sample $(n=14828)$ of young Korean adults free from hypertension or diabetes. They demonstrated that $\mathrm{MHO}$ was associated with increased CAC scores in multivariate analysis (OR: 2.26; 95\% CI 1.48-3.43), however adjustment for fasting blood glucose, systolic blood pressure, triglyceride levels, HDL-C, and HOMA-IR slightly reduced the associations, but they remained statistically significant. Further adjustment for LDL-C markedly attenuated the association between $\mathrm{MHO}$ and CAC, so that it was no longer statistically significant. The authors concluded that although MHO was associated with CAC, the relationship was mediated by metabolic risk factors, which is in line with our proposed distinction of primary and secondary risk factors in the previous section.

In summary, the MHO phenotype seems to be associated with a variety of markers of subclinical atherosclerotic disease, ranging from inflammatory "risk factors" to imaging techniques assessing subclinical atherosclerotic burden. However, the studies on carotid intima media thickness and MHO remain inconclusive, with some in favor, while others finding no association. Therefore we caution the reader against assuming this association to be evident in all cases, especially regarding carotid intima media thickness and the MHO phenotype. However, to the best of our knowledge, only three studies assessing coronary calcification have been reported in the literature, of 
Citation: Farooq A, Sorathia S,Shaharyar S, Roberson L, Feiz H (2015) Metabolically Healthy Obesity and the Fit/Fat Phenotype: Associations with Mortality, Subclinical Cardiovascular Disease and Approach to Treatment. J Metabolic Synd 4: 176. doi:http://dx.doi.org/ 10.4172/2167-0943.1000176

Page 5 of 7

which two demonstrated a significant association between MHO and CAC, whereas the third demonstrated an association only in unadjusted and partially adjusted models. This, coupled with the variety of markers that have been linked with MHO and CVD, offer reasonable evidence of increased subclinical disease burden in this population.

\section{The Role of Physical Fitness: The Fit/Fat Phenotype}

A wealth of evidence has linked decreased cardiorespiratory fitness (CRF) with increased all-cause mortality and worse health outcomes [42-44]. Interestingly, two systematic reviews $[42,43]$ examined the association of cardiorespiratory fitness with cardiovascular and allcause mortality, and both demonstrated that CRF was associated with a reduction in mortality, independently of BMI status. A recent meta- analysis performed by Barry et al. [44] lends further support to these findings. Barry et al. [44] pooled data from 10 studies $(\mathrm{N}=92,986)$, and demonstrated that those who were overweight but fit, did not have a statistically significant increased mortality risk (OR: 1.13; $95 \%$ CI 1.00-1.27) as compared to normal weight, fit individuals. Similarly, obese but fit individuals did not have an increased risk of mortality as compared to their normal weight, fit counterparts (OR: 1.21; 95\% CI 0.95-1.52). In agreement with these findings, Ortega et al. [45] noted that MHO (after accounting for physical fitness levels) was not associated with increased mortality as compared to the MHNW.

A little reflection on these results yields the following points of interest. Firstly, these findings fit with the model that obesity per se may not be a primary risk factor for the development of CVD, but may instead have a secondary or permissive role (Figure 3 ).

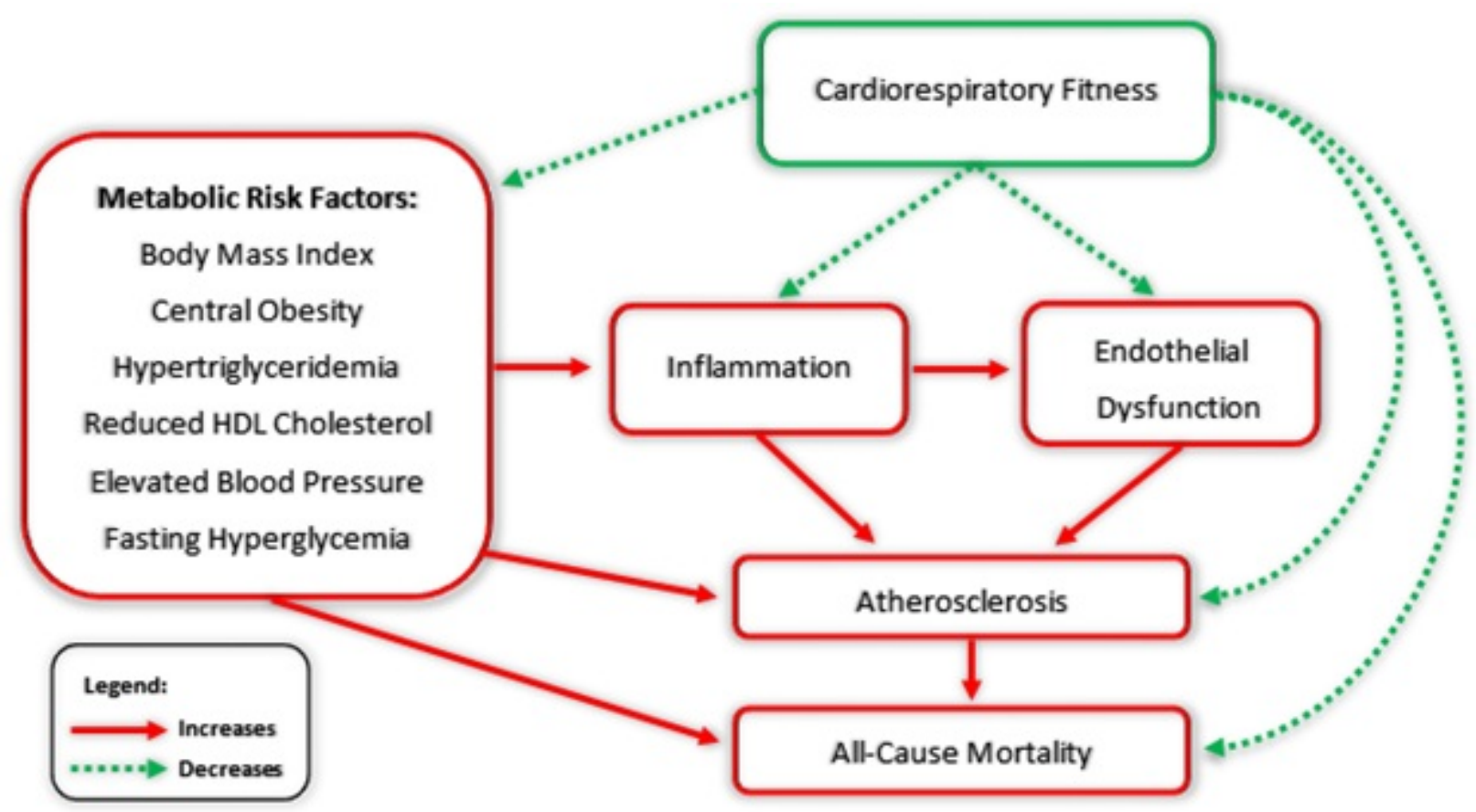

Figure 3: The Relationship of Metabolic Risk Factors and Cardiorespiratory Fitness with Atherosclerotic Disease - Theoretical Model.

Indeed, the finding that CRF completely mitigates the increased mortality risk in this population lends support to this claim. Secondly, this raises important considerations for the utility of physical activity and physical fitness levels - i.e., does adoption of increased physical activity levels impact mortality, obesity and metabolic health?

Of these questions, perhaps the easiest to answer is the relationship of physical activity with mortality. The notion that improved physical activity levels are associated with decreased mortality and improved health outcomes is self-evident and well documented [46-48]. Regarding the second question, achieving sustained significant weight loss by lifestyle changes is a highly variable intervention with a wide range of results. Although initially accompanied with a significant reduction in weight, most participants tend to regain lost weight over the subsequent years. A meta-analysis by Dombrowski et al. [49] demonstrated that lifestyle changes with or without drug therapy was associated with small, but significant sustained weight reduction over a 24 -month period. This was in line with a previous analysis by Galani et al. [50]. Similarly, a meta-analysis by Baillot et al. [51] demonstrated that long-term lifestyle interventions achieved a weight loss of $11.3 \mathrm{~kg}$ in those with Class II or III obesity. All three of these analyses further demonstrated that physical activity lifestyle changes were associated with improvements in metabolic risk profiles (waist circumference, fasting glucose, serum lipids, blood pressure) to varying degrees.

However, an analysis by Harrington et al. [52] demonstrated that intentional weight loss in the MHO was not associated with reductions in risk of mortality. A re-analysis of the Framingham Heart Study and the Tecumseh Community Study suggested that weight loss due to reduction in body fat may reduce all-cause mortality whereas weight loss as a result of a reduction in lean body mass may increase it [53]. These data underscore the fallacy of chasing weight goals while ignoring the method used to achieve it. Given this and the preceding data, the importance of including physical activity and fitness-based strategies in weight reduction cannot be understated. 
Citation: Farooq A, Sorathia S,Shaharyar S, Roberson L, Feiz H (2015) Metabolically Healthy Obesity and the Fit/Fat Phenotype: Associations with Mortality, Subclinical Cardiovascular Disease and Approach to Treatment. J Metabolic Synd 4: 176. doi:http://dx.doi.org/ $10.4172 / 2167-0943.1000176$

Page 6 of 7

Although the meta-analysis by Kramer et al. [24] noted an increased CVD risk in $\mathrm{MHO}$ individuals, that analysis was conducted on unadjusted data, which did not account for the impact of physical activity. The analysis by Barry et al. [44] and by Kramer et al. [24] cannot therefore be directly compared. Synthesis of these disparate viewpoints into a unified message for clinical practice remains an area of active research. In summary, current data suggests, with caveats, that improved physical activity and fitness is associated with

a) Reductions in weight,

b) Reductions in nearly all metabolic risk factors and

c) Reduction in all-cause mortality.

\section{Putting it all Together - Conclusions}

The present review demonstrates that the MHO phenotype may not be a benign condition, as it is associated with increased mortality and with measures of subclinical cardiovascular disease. However, the issue of physical fitness and its impact on MHO risk has not yet been conclusively settled. At the same time, the MHO phenotype is noted to be associated with increased physical activity/fitness levels as compared to the MUO, lending support to the claim that physical activity/fitness is involved in the risk in these groups. Furthermore, given the demonstrated utility of physical fitness/activity in reducing obesity, metabolic derangements and mortality, improving physical activity levels should be an essential component of any therapeutic or prevention efforts.

\section{Implications for research}

We reiterate the findings of previous reports emphasizing the need for adherence to uniform criteria for defining metabolic syndrome and its associated phenotypes in order to facilitate direct comparison of results. Secondly, we note the relative lack of literature assessing the relationship of MHO with subclinical disease parameters in the context of physical activity/fitness levels and we advocate inclusion of a physical fitness model into the definition of the metabolic syndrome. Thirdly, we note the need for longitudinal studies assessing both metabolic status and physical activity according to unified criteria to reconcile the differences observed in the meta-analyses cited in our commentary.

\section{Implications for clinical practice}

The absence of metabolic abnormalities should not reassure physicians regarding the CVD risk of their patients; instead efforts should be directed to reverse this condition. The authors recommend "chasing labs and weight" rather than "chasing weight" when setting goals for patients, since the benefits of improved physical activity and fitness extend beyond those of simple weight reduction. Bearing in mind that individuals with MHO may commonly have one metabolic abnormality, preventive goals should be aimed at both reducing weight and reducing metabolic derangements, for which physical activity seems ideally suited. The authors advise against setting treatment goals solely on weight, since elimination of obesity without elimination of corresponding metabolic risk factors would reclassify patients into the MUNW group, which has a mortality risk which is comparable to that of the MHO.

\section{References}

1. World Health Statistics by World Health Organization. 2014; http:// apps.who.int/iris/bitstream/10665/112738/1/9789240692671_eng.pdf

2. Ogden CL, Carroll MD, Kit BK, Flegal KM (2014) Prevalence of childhood and adult obesity in the United States, 2011-2012. JAMA 311: 806-814.

3. Flegal KM, Kit BK, Orpana H, Graubard BI (2013) Association of allcause mortality with overweight and obesity using standard body mass index categories: a systematic review and meta-analysis. JAMA 309: 71-82.

4. Vague J (1947) La différenciation sexuelle, facteur determinant des formes de l'obésité. (Sexual differentiation as a factor determining the forms of obesity). Presse Med 30: 339-340.

5. Alberti KG, Eckel RH, Grundy SM, (2009) Harmonizing the metabolic syndrome: a joint interim statement of the International Diabetes Federation Task Force on Epidemiology and Prevention; National Heart, Lung, and Blood Institute; American Heart Association; World Heart Federation; International Atherosclerosis Society; and International Association for the Study of Obesity. Circulation 120: 1640-1645.

6. Sims EA (2001) Are there persons who are obese, but metabolically healthy? Metabolism 50: 1499-1504.

7. Karelis AD, St-Pierre DH, Conus F, Rabasa-Lhoret R, Poehlman ET (2004) Metabolic and body composition factors in subgroups of obesity: what do we know? J Clin Endocrinol Metab 89: 2569-2575.

8. Karelis AD, Faraj M, Bastard JP, St-Pierre DH, Brochu M, et al. (2005) The metabolically healthy but obese individual presents a favorable inflammation profile. J Clin Endocrinol Metab 90: 4145-4150.

9. Meigs JB, Wilson PW, Fox CS, Vasan RS, Nathan DM, et al. (2006) Body mass index, metabolic syndrome, and risk of type 2 diabetes or cardiovascular disease. J Clin Endocrinol Metab 91: 2906-2912.

10. Karelis AD (2008) Metabolically healthy but obese individuals. Lancet 372: 1281-1283.

11. Blüher M (2010) The distinction of metabolically 'healthy' from 'unhealthy' obese individuals. Curr Opin Lipidol 21: 38-43.

12. Primeau V, Coderre L, Karelis AD, Brochu M, Lavoie ME, et al. (2011) Characterizing the profile of obese patients who are metabolically healthy. Int J Obes (Lond) 35: 971-981.

13. Karelis AD (2011) To be obese--does it matter if you are metabolically healthy? Nat Rev Endocrinol 7: 699-700.

14. Ruderman N, Chisholm D, Pi-Sunyer X, Schneider S (1998) The metabolically obese, normal-weight individual revisited. Diabetes 47: 699-713.

15. Conus F, Allison DB, Rabasa-Lhoret R, St-Onge M, St-Pierre DH, et al. (2004) Metabolic and behavioral characteristics of metabolically obese but normal-weight women. J Clin Endocrinol Metab 89: 5013-5020.

16. Succurro E, Marini MA, Frontoni S, Hribal ML, Andreozzi F, et al. (2008) Insulin secretion in metabolically obese, but normal weight, and in metabolically healthy but obese individuals. Obesity (Silver Spring) 16: 1881-1886.

17. Lee K (2009) Metabolically obese but normal weight (MONW) and metabolically healthy but obese (MHO) phenotypes in Koreans: characteristics and health behaviors. Asia Pac J Clin Nutr 18: 280-284.

18. Lee SH, Han K, Yang HK, Kim MK, Yoon KH, et al. (2015) Identifying subgroups of obesity using the product of triglycerides and glucose: the Korea National Health and Nutrition Examination Survey, 2008-2010. Clin Endocrinol (Oxf) 82: 213-220.

19. Du T, Yu X, Zhang J, Sun X (2015) Lipid accumulation product and visceral adiposity index are effective markers for identifying the metabolically obese normal-weight phenotype. Acta Diabetol.

20. Roberson LL, Aneni EC, Maziak W (2014) Beyond BMI: The "Metabolically healthy obese" phenotype \& its association with clinical/ subclinical cardiovascular disease and all-cause mortality -- a systematic review. BMC Public Health. 
Citation: Farooq A, Sorathia S,Shaharyar S, Roberson L, Feiz H (2015) Metabolically Healthy Obesity and the Fit/Fat Phenotype: Associations with Mortality, Subclinical Cardiovascular Disease and Approach to Treatment. J Metabolic Synd 4: 176. doi:http://dx.doi.org/ $10.4172 / 2167-0943.1000176$

Page 7 of 7

21. Pataky Z, Bobbioni-Harsch E, Golay A (2010) Open questions about metabolically normal obesity. Int J Obes (Lond) 34 Suppl 2: S18-23.

22. Seo MH, Rhee EJ (2014) Metabolic and cardiovascular implications of a metabolically healthy obesity phenotype. Endocrinol Metab (Seoul) 29: 427-434.

23. Wildman RP, Muntner P, Reynolds K (2008) The obese without cardiometabolic risk factor clustering and the normal weight with cardiometabolic risk factor clustering: prevalence and correlates of 2 phenotypes among the US population. Arch Intern Med 168: 1617-1624.

24. Kramer CK, Zinman B, Retnakaran R (2013) Are metabolically healthy overweight and obesity benign conditions?: A systematic review and meta-analysis. Ann Intern Med 159: 758-769.

25. Durward CM, Hartman TJ, Nickols-Richardson SM (2012) All-cause mortality risk of metabolically healthy obese individuals in NHANES III. J Obes 2012: 460321.

26. Shaharyar S, Roberson L, Jamal O (2015) Obesity and Metabolic Phenotypes (Metabolically Healthy and Unhealthy Variants) Are Significantly Associated with Prevalence of Elevated C-Reactive Protein and Hepatic Steatosis in a Large Healthy Brazilian Population. Journal of Obesity.

27. Heianza Y, Kato K, Kodama S (2014) Risk of the development of Type 2 diabetes in relation to overall obesity, abdominal obesity and the clustering of metabolic abnormalities in Japanese individuals: does metabolically healthy overweight really exist? The Niigata Wellness Study. Diabet Med.

28. Eshtiaghi R, Keihani S, Hosseinpanah F, Barzin M, Azizi F (2015) Natural course of metabolically healthy abdominal obese adults after 10 years of follow-up: the Tehran Lipid and Glucose Study. Int J Obes (Lond) 39: 514-519.

29. Kuk JL, Ardern CI (2009) Are metabolically normal but obese individuals at lower risk for all-cause mortality? Diabetes Care 32: 2297-2299.

30. Indulekha K, Surendar J, Anjana RM, Geetha L, Gokulakrishnan K, et al. (2015) Metabolic obesity, adipocytokines, and inflammatory markers in Asian Indians--CURES-124. Diabetes Technol Ther 17: 134-141.

31. Jung CH, Lee MJ, Hwang JY, Jang JE, Leem J, et al. (2014) Association of metabolically healthy obesity with subclinical coronary atherosclerosis in a Korean population. Obesity (Silver Spring) 22: 2613-2620.

32. Khan UI, Wang D, Thurston RC, Sowers M, Sutton-Tyrrell K, et al. (2011) Burden of subclinical cardiovascular disease in "metabolically benign" and "at-risk" overweight and obese women: the Study of Women's Health Across the Nation (SWAN). Atherosclerosis 217: 179-186.

33. Lind L, Siegbahn A, Ingelsson E, Sundström J, Arnlöv J (2011) A detailed cardiovascular characterization of obesity without the metabolic syndrome. Arterioscler Thromb Vasc Biol 31: e27-34.

34. Marini MA, Succurro E, Frontoni S (2007) Metabolically healthy but obese women have an intermediate cardiovascular risk profile between healthy nonobese women and obese insulin-resistant women. Diabetes Care: 2145-2147.

35. Wildman RP, Kaplan R, Manson JE, Rajkovic A, Connelly SA, et al. (2011) Body size phenotypes and inflammation in the Women's Health Initiative Observational Study. Obesity (Silver Spring) 19: 1482-1491.

36. Detrano R, Guerci AD, Carr JJ, Bild DE, Burke G, et al. (2008) Coronary calcium as a predictor of coronary events in four racial or ethnic groups. N Engl J Med 358: 1336-1345.

37. Erbel R, Mohlenkamp S, Moebus S (2010) Coronary risk stratification, discrimination, and reclassification improvement based on quantification of subclinical coronary atherosclerosis: the Heinz Nixdorf Recall study. J Am Coll Cardiol 56: 1397-1406.

38. Polonsky TS, McClelland RL, Jorgensen NW, Bild DE, Burke GL, et al. (2010) Coronary artery calcium score and risk classification for coronary heart disease prediction. JAMA 303: 1610-1616.

39. Nasir K, Shaw LJ, Budoff MJ, Ridker PM, Peña JM (2012) Coronary artery calcium scanning should be used for primary prevention: pros and cons. JACC Cardiovasc Imaging 5: 111-118.

40. Greenland P, Alpert JS, Beller GA (2010) ACCF/AHA guideline for assessment of cardiovascular risk in asymptomatic adults: a report of the American College of Cardiology Foundation/American Heart Association Task Force on Practice Guidelines. Circulation.122: e584-636.

41. Chang Y, Kim BK, Yun KE, Cho J, Zhang Y, et al. (2014) Metabolicallyhealthy obesity and coronary artery calcification. J Am Coll Cardiol 63: 2679-2686.

42. Fogelholm M (2010) Physical activity, fitness and fatness: relations to mortality, morbidity and disease risk factors. A systematic review. Obes Rev 11: 202-221.

43. Pedersen BK (2007) Body mass index-independent effect of fitness and physical activity for all-cause mortality. Scand J Med Sci Sports 17: 196-204.

44. Barry V, Baruth M, Beets MW, Durstine JL, Liu J, et al. (2014) Fitness vs. fatness on all-cause mortality: a meta-analysis. Prog Cardiovasc Dis 56: 382-390.

45. Ortega FB, Lee DC, Katzmarzyk PT, Ruiz JR, Sui X, et al. (2013) The intriguing metabolically healthy but obese phenotype: cardiovascular prognosis and role of fitness. Eur Heart J 34: 389-397.

46. Samitz G, Egger M, Zwahlen M (2011) Domains of physical activity and all-cause mortality: systematic review and dose-response meta-analysis of cohort studies. Int J Epidemiol 40: 1382-1400.

47. Woodcock J, Franco OH, Orsini N, Roberts I (2011) Non-vigorous physical activity and all-cause mortality: systematic review and metaanalysis of cohort studies. Int J Epidemiol 40: 121-138.

48. Löllgen H, Böckenhoff A, Knapp G (2009) Physical activity and all-cause mortality: an updated meta-analysis with different intensity categories. Int J Sports Med 30: 213-224.

49. Dombrowski SU, Knittle K, Avenell A, Araújo-Soares V, Sniehotta FF (2014) Long term maintenance of weight loss with non-surgical interventions in obese adults: systematic review and meta-analyses of randomised controlled trials. BMJ 348: g2646.

50. Galani C, Schneider H (2007) Prevention and treatment of obesity with lifestyle interventions: review and meta-analysis. Int J Public Health 52: 348-359.

51. Baillot AO, Romain AJ, Boisvert-Vigneault K, Audet M, Baillargeon JP, et al. (2015) Effects of Lifestyle Interventions That Include a Physical Activity Component in Class II and III Obese Individuals: A Systematic Review and Meta-Analysis. PLoS One 10: e0119017.

52. Harrington M, Gibson S, Cottrell RC (2009) A review and meta-analysis of the effect of weight loss on all-cause mortality risk. Nutr Res Rev 22: 93-108.

53. Allison DB, Zannolli R, Faith MS, Heo M, Pietrobelli A, et al. (1999) Weight loss increases and fat loss decreases all-cause mortality rate: results from two independent cohort studies. Int J Obes Relat Metab Disord 23: 603-611. 